\title{
Laboratory Diameteral Fatigue Performance of Stone Matrix Asphalt with Cellulose Oil Palm Fiber
}

\author{
Ratnasamy Muniandy and Bujang B.K. Huat \\ Department of Civil Engineering, University Putra Malaysia \\ 43400 UPM, Serdang, Selangor, Malaysia
}

\begin{abstract}
Stone Matrix Asphalt (SMA) is a gap-graded mix that is gaining popularity worldwide. Generally, gap graded mixes are thought to be weak in fatigue resistance. In this study, cellulose fibers were pre-blended in PG64-22 binder with fiber proportions of $0.2 \%, 0.4 \%, 0.6 \%, 0.8 \%$ and $1.0 \%$ by weight of aggregates. The fiber-modified binder showed improved rheological properties and showed that the PG64-22 binder can be modified and raised to PG70-22 grade. The cellulose oil palm fiber (COPF) was found to improve the diameteral fatigue performance of SMA design mix. The fatigue life increased to a maximum at a fiber content of about $0.6 \%$, whilst the tensile stress and stiffness also showed a similar trend in performance. The initial strains of the mix were lowest at a fiber content of $0.6 \%$.
\end{abstract}

Key words: Cellulose oil palm fiber, diameteral fatigue, stone mastic asphalt

\section{INTRODUCTION}

Asphalt pavements in general are facing serious distress problems worldwide. So much has been done to improve the quality of the mix through research and innovations. However, the problem of fatigue cracking is still persistent on asphalt roads.

In Malaysia, fatigue or tensile cracking along wheel paths of vehicles are predominant on Malaysian roads as compared with other forms of distress. This is primarily due to accelerated loading from trucks ${ }^{[1-3]}$, which is causing the authorities millions of ringgit (1RM is approximately equal to 3.8 USD) on road maintenance alone. This situation is further aggravated by the traditional use of soft 80-100 penetration binders, which are poor in shear strength; made worst by the hot wet nature of the Malaysian climate.

Several additives like polymers have been very effective in enhancing the asphalt mix performance to a large extent. These additives however are very expensive and tend to increase the overall cost of the pavement construction rather drastically.

Cellulose fibers in general have been extensively investigated by various research groups in many countries to ascertain their suitability as substitutes for conventional synthetic fibers such as glass and asbestos in the production of roof slabs and thin-sectioned wall and ceiling panel ${ }^{[4,5]}$. Fibers from coconuts, sisal, jute, sugar cane, banana, wood, palms, flax and elephant grass are among the many studied by various investigators. However, the effect of cellulose oil palm fibers (COPF) in the fatigue performance of Stone Mastic Asphalt (SMA) other than the traditional draindown study is worth investigating.
Malaysia is one of the largest producers of palm oil in the world. At present, the EFB (empty fruit branch of the oil palm) is either burned as fuel for the boiler or used for mulching purposes in the field ${ }^{[6]}$. However restrictions on burning have developed mulching of EFB in the field that creates environmental problem. It now costs a palm oil mill approximately RM 15 a metric ton to dispose off the $\mathrm{EFB}^{[6]}$.

Stone Matrix Asphalt (SMA) is a gap-graded mix that is gaining popularity world-wide. Traditionally, SMA is made using hard, crushed, durable and high quality stones of roughly cubical shape. The stones are then glued with a durable, moisture-resistant mortar of just the right quantity to provide stone-on-stone contact among the coarse aggregate particles. Stone Mastic Asphalt was first devised in Europe in the 80's. In the United States, the SMA technology started an evolution in the early $90 \mathrm{~s}$ and has been widely used since $\mathrm{e}^{[7-11]}$. Most of the reports by the researchers highlighted the mixtures great potential in resisting permanent deformation or rutting, but ignored any potential fatigue resistance of the SMA.

This study describes an attempt to evaluate the effect of cellulose oil palm fibers (COPF) in the fatigue performance of SMA. The cellulose oil palm fibers were pre-blended in PG64-22 binder with fiber proportions of $0.2,0.4,0.6,0.8$ and $1.0 \%$ by weight of aggregates. A fatigue test was then performed on 100 $\mathrm{mm}$ diameteral SMA design mix specimen with varying proportions of COPF.

Materials selection and properties of fiber modified asphalt: Aggregate and asphalt are the two basic components of any asphalt mixture, including gap-

Corresponding Author: Bujang B.K. Huat, Department of Civil Engineering, University Putra Malaysia, 43300 Serdang Selangor, Malaysia, Tel: 603-8946368, Fax: 603-86567129 
graded mixtures such as SMA. Unlike the traditional dense graded mixes, SMA is known to provide good rut resistance. However, SMA mixes showed poor fatigue resistance due to its coarse aggregate matrix. Since SMA is sensitive to the type of materials selected, stringent tests were performed to ensure good quality of mix.

Cellulose oil palm fiber: The cellulose oil palm fibers (COPF) were made from empty fruit bunch (EFB) by way of various methods of pulping, of which the Chemical-R type (Fig. 1) was found to produce the best results $\left[^{6}\right]$. The oil retaining ability of the cellulose oil palm fibers were determined using Dr. Scallenburg's motor oil test. Appropriate motor oil grade was heated in a beaker up to $160^{\circ} \mathrm{C}$ and was poured onto the cellulose oil palm fiber specimens in a specified mesh. The oil drain down was recorded against time. The cellulose fiber properties and size distribution are shown in Table 1.

\begin{tabular}{lll} 
Table 1: & Cellulose oil palm fiber (COPF) size distribution \\
\hline No & Sieve size $(\mu \mathrm{m})$ & COPF \\
\hline 1 & 580 & 90 \\
2 & 425 & 80 \\
3 & 250 & 65 \\
4 & 180 & 55 \\
5 & 150 & 35 \\
6 & 106 & 20 \\
7 & Moisture Content & $<5 \%$ \\
8 & pH-Value & $7 \pm 5 \%$ \\
9 & Ash Content & $3.5 \%$ \\
\hline
\end{tabular}

Fiber modified asphalt properties: The traditional 80100 penetration asphalt binder was blended with various percentages of cellulose fibers and analyzed for their physical properties. Fibers selected based on good oil retaining properties (Chemical $\mathrm{R}$ type), were blended in proportions of $0.2 \%$ (up to $1.0 \%$ ) and were tested for their physical properties. Table 2 shows the physical properties of fiber modified asphalt. It can be seen that the penetration of the fiber modified asphalt dropped from 92 for unmodified to 60 for $1 \%$ fiber modified asphalt, approximately (35\%). The softening point and the flash point values increased by as much as $24 \%$ and $9 \%$ respectively. The Brookfield viscosity test at $60^{\circ} \mathrm{C}$ was rather difficult since the fiber modified asphalt became very stiff. However, the viscosity at $160^{\circ} \mathrm{C}$ showed remarkable increase from $237 \mathrm{cP}$ to $9042 \mathrm{cP}$. These basic properties of fiber modified asphalt binder were found to be satisfactory for further analysis using the Super Pave Dynamic Shear Rheometer (DSR). A performance graded PG64-22 binder which was equivalent to the traditional 80-100 penetration asphalt binder was used in this case.

The viscosity of the unmodified PG64-22 binder as shown in Fig. 2 increased to an optimum at $0.6 \%$ fiber content at $165^{\circ} \mathrm{C}$ while at $135^{\circ} \mathrm{C}$ the fiber modified asphalt binder showed a continued increase. The changes in viscosity of asphalt with various fiber proportions are shown in Fig. 3.

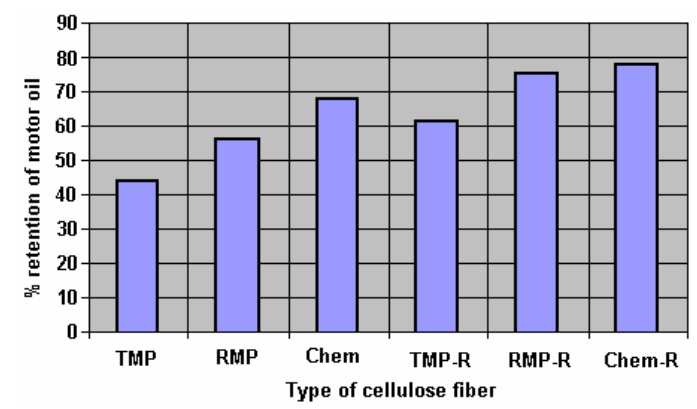

TMP - Thermal mechanical pulping

RMP- Refinery mechanical pulping

Chem-Chemically pulped fibers

TMP-R-Themal mechanical pulping and refined

RMP-R-Refinery mechanical pulping and refined

Chem-R-Chemically pulped and refined

Fig. 1: Oil retention of various fibers

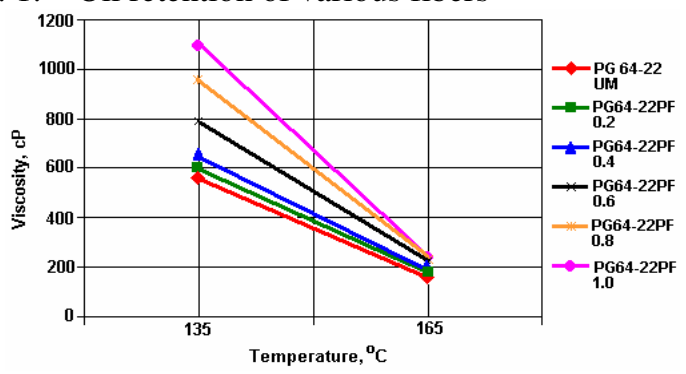

Fig. 2: Viscosity temperature relationship of fiber modified asphalt

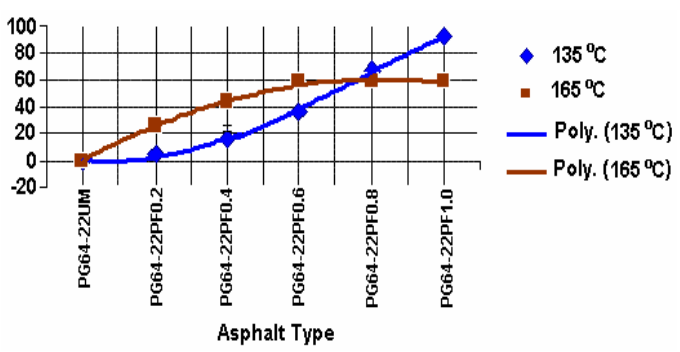

Fig. 3: Viscosity change vs type of asphalt blend

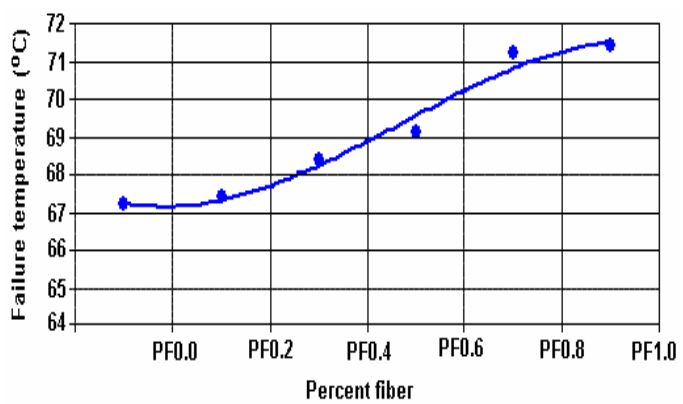

Fig. 4: Failure temperature vs. percent fiber

As above, it was observed that at $135^{\circ} \mathrm{C}$ the change in viscosity displayed an increasing trend, whilst at $165^{\circ} \mathrm{C}$ the increase optimized at about $0.6-0.8 \%$ fiber content.

Figure 4 shows the failure temperature against percent of fiber. The failure temperature of PG64-22 grade asphalt increased as the percentage of fiber 
Am. J. Appl. Sci., 3 (9): 2005-2010, 2006

Table 2: Summary of physical properties of fiber modified asphalt

\begin{tabular}{llllllll}
\hline Type of Test & Standard used & $*$ PF00 & PF0.2 & PF0.4 & PF0.6 & PF0.8 & PF1.0 \\
\hline Penetration @ $25^{\circ} \mathrm{C}$ & ASTM D5 & 92 & 84 & 76 & 68 & 62 & 60 \\
Softening Point, ${ }^{\circ} \mathrm{C}$ & ASTM D36 & 48.6 & 50.3 & 53.4 & 57.6 & 58.5 & 60.1 \\
Flash Point, ${ }^{\circ} \mathrm{C}$ & ASTM D92 & 280 & 282.3 & 286.4 & 290.1 & 293.6 & 305 \\
Fire Point, ${ }^{\circ} \mathrm{C}$ & ASTM D92 & $>310$ & & & & & \\
Thin Film Oven & ASTM D1754 & $0.01 \%$ & 0.01 & 0.025 & 0.031 & 0.048 & 0.05 \\
Specific Gravity & ASTM D70 & 1.025 & 1.028 & 1.03 & 1.03 & 1.028 & 1.02 \\
Viscosity @ $60^{\circ} \mathrm{C}$ & ASTM D4402 & 350000 & NA & NA & NA & NA & NA \\
Viscosity @ $160^{\circ} \mathrm{C}$ & ASTM D4402 & 237 & 510 & 1895 & 2480 & 5058 & 9042 \\
\hline
\end{tabular}

Table 3: Summary of DSR results of PG64-22 with fiber at $64^{\circ} \mathrm{C}$

\begin{tabular}{|c|c|c|c|c|c|c|c|c|c|c|c|}
\hline No & Sample & Ang.freq & Time & Test temp & Fail temp & Osc.stress & $\%$ strain & $\mathrm{G}^{*} / \sin \delta$ & $\mathrm{G}^{*}$ & $\delta$ & $\mathrm{G}^{*} \sin \delta$ \\
\hline 1 & PF0.0 & 9.991 & 39.81 & 64 & & 179.6 & 12.085 & 1.491 & 1488 & 86.76 & 1486 \\
\hline 2 & PF0.2 & 9.991 & 39.91 & 64 & & 182.5 & 11.911 & 1.539 & 1536 & 86.36 & 1533 \\
\hline 3 & PF0.4 & 9.991 & 39.86 & 64 & & 210.9 & 12.024 & 1.763 & 1758 & 85.79 & 1753 \\
\hline 4 & PF0.6 & 9.991 & 39.88 & 64 & & 222.9 & 11.976 & 1.873 & 1867 & 85.16 & 1806 \\
\hline 5 & PF0.8 & 9.991 & 39.95 & 64 & & 299.2 & 11.918 & 2.529 & 2517 & 84.53 & 2506 \\
\hline 6 & PF1.0 & 9.991 & 39.91 & 64 & & 325.9 & 12.155 & 2.7 & 2688 & 84.45 & 2675 \\
\hline
\end{tabular}

Table 4: Summary of DSR results of PG64-22 with fiber at $70^{\circ} \mathrm{C}$

\begin{tabular}{llllllllllll}
\hline No & Sample & Ang. freq & Time & Temp & Fail temp & Osc.stress & $\%$ strain & $\mathrm{G}^{*} / \sin \delta$ & $\mathrm{G}^{*}$ & $\delta$ & $\mathrm{G}^{*} \sin \delta$ \\
\hline 1 & UMB & 9.991 & 39.92 & 69.9 & 67.2 & 84.43 & 12.018 & 0.7031 & 702.4 & 87.45 & 701.7 \\
2 & PF0.2 & 9.991 & 40.03 & 70.1 & 67.4 & 86.59 & 11.969 & 0.7248 & 723.9 & 87.11 & 723 \\
3 & PF0.4 & 9.991 & 39.9 & 70 & 68.4 & 97.76 & 12.048 & 0.8145 & 813 & 86.48 & 812 \\
4 & PF0.6 & 9.991 & 39.77 & 70 & 69.1 & 106.2 & 12.019 & 0.889 & 886.6 & 85.77 & 884 \\
5 & PF0.8 & 9.991 & 39.74 & 69.9 & 71.2 & 138.2 & 11.985 & 1.161 & 1157 & 85.33 & 1153 \\
6 & PF1.0 & 9.991 & 39.78 & 70.1 & 71.4 & 144.9 & 12.093 & 1.206 & 1202 & 85.32 & 1198 \\
\hline
\end{tabular}

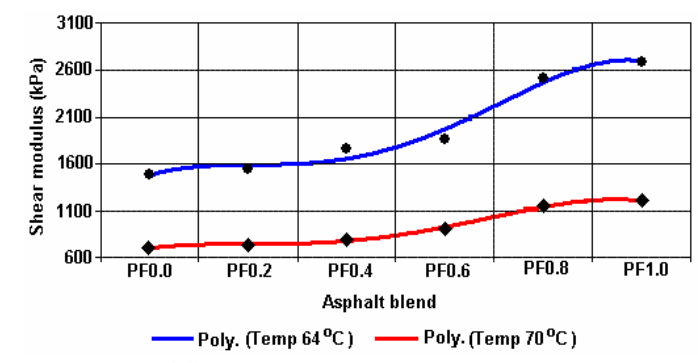

PF - Percentage of fiber (\%)

Fig. 5: Complex shear modulus vs. type of blend

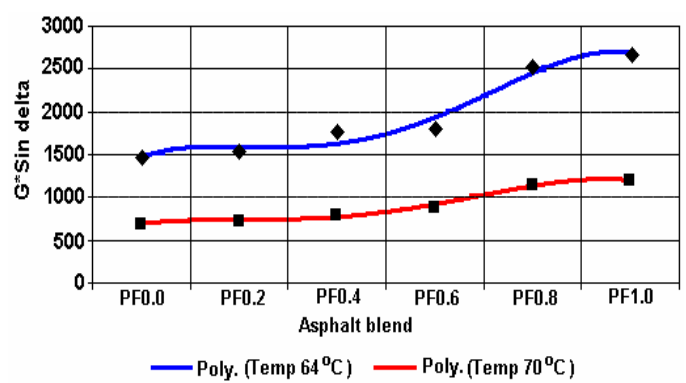

PF - Percentage fiber $(\%)$

Fig. 6: $\mathrm{G}^{*}$ sin delta vs type of blend

increased up to about $0.8 \%$. The maximum failure temperature attained was a little more than $71^{\circ} \mathrm{C}$. This indicates that the cellulose oil palm fiber can be used as an additive to modify PG64-22 grade asphalt to PG7022 without using polymers.

DSR has become an excellent tool in analyzing binder materials for permanent deformation and fatigue performance. Two other important parameters that can be obtained from the DSR tests are the complex modulus, $\mathrm{G}^{*}$ and the phase angle, $\delta$. The phase angle is an indicator of the visco-elastic behavior of binders. The fatigue characteristic of binder is calculated from the DSR's complex modulus, $G^{*}$. The higher the product of $\mathrm{G}^{*}$ and $\operatorname{Sin} \delta$ the higher the fatigue resistance. Table 3 and 4 show a summary of DSR rheological properties of cellulose fiber modified asphalt binders at $64^{\circ} \mathrm{C}$ and $70^{\circ} \mathrm{C}$ respectively.

The complex shear modulus plot against fiber content is shown in Fig. 5. As shown, the shear modulus increases with increase in the fiber content. The improvement in fatigue property of various fiber proportions is shown in Fig. 6. The fatigue resistance from fibers showed a slight increase from $0 \%$ to $0.4 \%$, but however, there was remarkable increase in fatigue resistance from $0.4 \%$ to $0.8 \%$ fiber content.

Aggregates: Aggregates makeup about 93 to 94 percent by weight of total mix in SMA mixes. Therefore serious consideration should be given to the type and quality of aggregates selected for the study. Although various types of aggregate stones such as granite, basalt, quartzite and limestone are found in Malaysia, granite stones form the bulk of the road and building construction in Malaysia. Based on prior studies carried out on aggregates, granite aggregates from the Negeri Road Stone Quarry (Negeri Sembilan, Malaysia) were selected to be used in this study. A total of four gradations (G1 - G4) were selected within the specification as shown in Table 5, with the lower, upper, mean and combined gradations shown. The physical properties of granite aggregates used in SMA are shown in Table 6 . The aggregate had passed all the tests required for the SMA mix design. 
Am. J. Appl. Sci., 3 (9): 2005-2010, 2006

Table 5: Selected gradations for the SMA mix design

\begin{tabular}{|c|c|c|c|c|}
\hline Sieve sizes & $\begin{array}{c}\text { Lower } \\
\text { boundary } \\
\text { (G1) }\end{array}$ & $\begin{array}{c}\text { Upper } \\
\text { boundary } \\
\text { (G2) }\end{array}$ & $\begin{array}{l}\text { Desired } \\
\text { Mean } \\
\text { (G3) }\end{array}$ & $\begin{array}{c}\text { Stockpile } \\
\text { blend } \\
\text { (G4) }\end{array}$ \\
\hline 19 & 100 & 100 & 100 & 100 \\
\hline 14 & 85 & 95 & 90 & 83.6 \\
\hline 10 & 60 & 75 & 67.5 & 64.6 \\
\hline 6.7 & 25 & 32 & 25 & 30.9 \\
\hline 5 & 16 & 22 & 19 & 21.3 \\
\hline 2.36 & 14 & 19 & 16.5 & 16.5 \\
\hline 0.6 & 12 & 15 & 13.5 & 12.3 \\
\hline 0.3 & 9 & 12 & 10.5 & 11.1 \\
\hline 0.075 & 8 & 10 & 9 & 9.6 \\
\hline $\begin{array}{l}\% \text { Coarse } \\
\text { (retained on } \\
6.7 \mathrm{~mm} \text { ) }\end{array}$ & 75 & 68 & 71.5 & 69 \\
\hline $\begin{array}{l}\% \text { Coarse } \\
\text { (retained on } \\
2.36 \mathrm{~mm} \text { ) }\end{array}$ & 86 & 81 & 83.5 & 83 \\
\hline $\begin{array}{l}\% \text { Fines } \\
\text { (retained on } \\
200 \text { ) }\end{array}$ & 6 & 9 & 7.5 & 6.9 \\
\hline$\%$ Filler & 8 & 10 & 9 & 9.6 \\
\hline
\end{tabular}

\begin{tabular}{|c|c|c|c|c|}
\hline $\begin{array}{l}\text { Type of } \\
\text { Test }\end{array}$ & $\begin{array}{l}\text { Standard } \\
\text { used }\end{array}$ & $\begin{array}{l}\text { Results } \\
\text { obtained }\end{array}$ & Requirement & Remarks \\
\hline LA & $\begin{array}{l}\text { ASTM } \\
\text { C131 }\end{array}$ & $22.1 \%$ & $<30 \%$ & Suitable \\
\hline AIV & $\begin{array}{l}\text { BS812: } \\
\text { Part3 }\end{array}$ & $9.9 \%$ & $<15 \%$ & Suitable \\
\hline $\mathrm{ACV}$ & $\begin{array}{l}\text { BS812: } \\
\text { Part3 }\end{array}$ & $19.8 \%$ & $<30 \%$ & Suitable \\
\hline PSV & $\begin{array}{l}\text { BS812: } \\
\text { Part3 }\end{array}$ & 50.75 & $>40$ & Suitable \\
\hline Soundness & $\begin{array}{l}\text { BS812: } \\
\text { Part3 }\end{array}$ & $5.23 \%$ & $<12 \%$ & Suitable \\
\hline $\begin{array}{l}\text { Flakiness } \\
\text { Index } \\
(3: 1)\end{array}$ & $\begin{array}{l}\text { BS812: } \\
\text { Part3 }\end{array}$ & $14.89 \%$ & $<20 \%$ & Suitable \\
\hline $\begin{array}{l}\text { Specific } \\
\text { Gravity }\end{array}$ & $\begin{array}{l}\text { ASTM } \\
\text { C127 }\end{array}$ & 2.603 & $>2.60$ & Suitable \\
\hline $\begin{array}{l}\text { Angularity } \\
\text { Number }\end{array}$ & $\begin{array}{l}\text { BS812: } \\
\text { Part3 }\end{array}$ & 6 & $6-9$ & Suitable \\
\hline
\end{tabular}

Sample preparation and test program: Cylindrical specimens of $100 \mathrm{~mm}$ diameter were prepared with asphalt contents ranging from $5.5 \%$ to $7.5 \%$ with an increment of $0.5 \%$; three specimens were prepared at each binder content. A total of 360 specimens were prepared for the four selected gradations with and without the cellulose oil palm fibers. The fiber content was varied from $0 \%$ to $1.0 \%$ with an increment of $0.2 \%$ fiber. The preparations of the specimens were in accordance with Marshall method of mix design ${ }^{[12]}$. All specimens were prepared using the Marshall Compacting procedure of 50 blows. The optimum asphalt content was determined by testing the samples for stability, resilient modulus, bulk specific gravity and air voids in accordance with modified Asphalt Institute. The performance of the selected gradations with and without cellulose oil palm fibers showed a varied trend. The stability values of the SMA ranged from $5 \mathrm{kN}$ to $6.8 \mathrm{kN}$, with resilient modulus in the range of range $2175 \mathrm{MPa}$ to $3060 \mathrm{MPa}$. However, the SMA mixes
Table 7: Fatigue test parameters for the SMA mix

\begin{tabular}{ll}
\hline Parameter & Range \\
\hline Temperature, ${ }^{\circ} \mathrm{C}$ & $30,40,50$ \\
Preconditioning Pulse & 5 \\
Pulse Width, ms & 2000 \\
Strain, $10^{-6}$ & $1-100$ \\
Poisson's Ratio & 0.4 \\
Force, N & $1000 \mathrm{~N}, 1500 \mathrm{~N}$ \\
Rise Time, ms & 50 \\
\hline
\end{tabular}

with cellulose oil palm fibers displayed a higher performance in terms of stability and resilient modulus. The stability values ranged from $6.7 \mathrm{kN}$ to $11.6 \mathrm{kN}$. The resilient modulus values showed a range between $3250 \mathrm{MPa}$ and $4350 \mathrm{MPa}$. The optimum asphalt content for SMA mixes without the cellulose oil palm fiber was slightly lower than those with cellulose fibers. SMA without fibers had an optimum asphalt content ranging from $6.39 \%$ to $6.69 \%$, whilst SMA mixes with cellulose oil palm fibers had a range of $6.30 \%$ to $6.84 \%$. Of the four gradations gradation, G4 showed the best performance both with and without cellulose fibers. Fatigue study on cellulose oil palm fibers were carried out using gradation G4.

With the optimum asphalt content determined, a total of 108 specimens were made for six sets of 18 specimens each with one fiber content. Cellulose oil palm fiber of sizes between 50 and 100 micron and processed using the Chem- $\mathrm{R}$ technique were used by proportion of $0,0.2,0.4,0.6,0.8$ and $1.0 \%$ by weight of the aggregate. The specimens were tested at three temperatures of 30,40 and $50^{\circ} \mathrm{C}$ and two load levels of $1000 \mathrm{~N}$ and $1500 \mathrm{~N}$.

A repeated load indirect tensile (fatigue) test was performed on the SMA cylindrical samples in accordance with ASSHTO-TP8-99, using an IPC Material Testing Apparatus (MATTA). The machine with a maximum loading capacity of $4.5 \mathrm{kN}$ force had a strain setting range of 10-100 micro strains, a rise time range of $30 \mathrm{~ms}-120 \mathrm{~ms}$ and a force setting range of 465 $\mathrm{N}-1864 \mathrm{~N}$ for cyclic loading. The fatigue parameter settings used in the SMA fatigue testing are shown in Table 7.

\section{RESULTS AND DISCUSSION}

Figure 7 shows the fatigue lives of SMA mixes against the percentage of fibers at various temperatures. The mixes displayed increased fatigue resistance with an increase in cellulose fiber content up to $0.6 \%$. This increased fatigue resistance is displayed in all specimens tested at $30^{\circ} \mathrm{C}, 40^{\circ} \mathrm{C}$ and $50^{\circ} \mathrm{C}$ with various load durations.

The initial strain of the specimens (Fig. 8) showed distinctive improvement with fiber increment at various temperatures and load. A drop in initial strain was observed for fiber percentages up to $0.6 \%$ before the initial strain started increasing. This indicates that the tensile strength of the mix improved and reached a maximum at a fiber content of $0.6 \%$. 


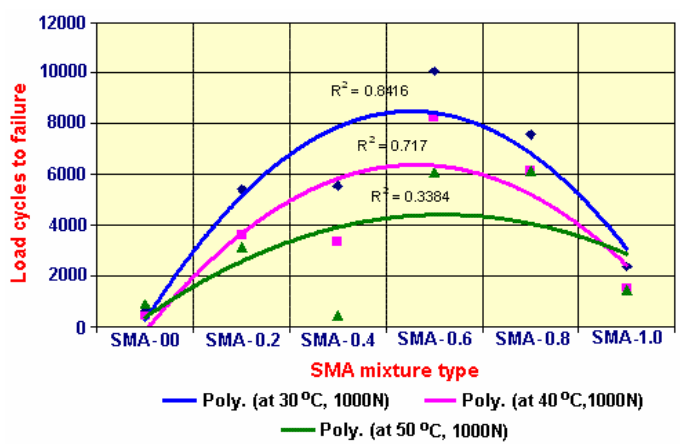

(a) applied load $1000 \mathrm{~N}$

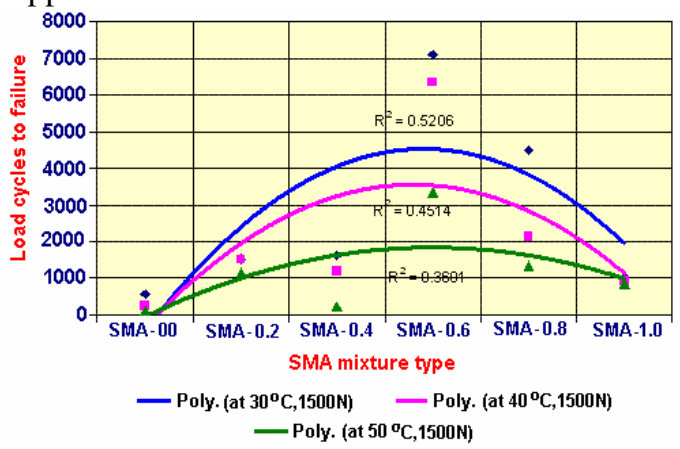

(b) Applied load $1500 \mathrm{~N}$

Fig. 7: Load cycles to failure vs. asphalt blend for various temperatures

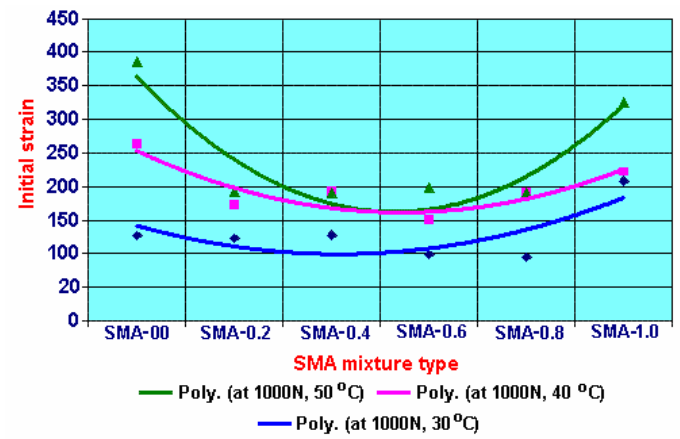

(a) Applied load $1000 \mathrm{~N}$

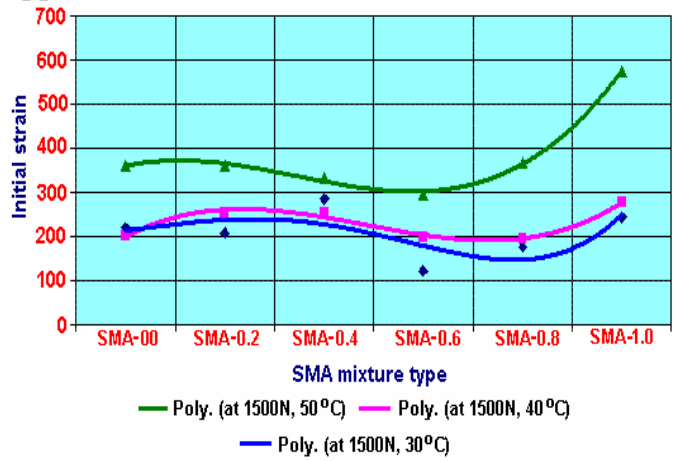

(b) Applied load $1500 \mathrm{~N}$

Fig. 8: Initial strain vs. asphalt blend for various temperatures

The initial stiffness, which is a ratio of initial tensile stress over initial tensile strain, very often can give a good indication of the mixes fatigue performance against repeated loading. Figure 9 shows initial stiffness

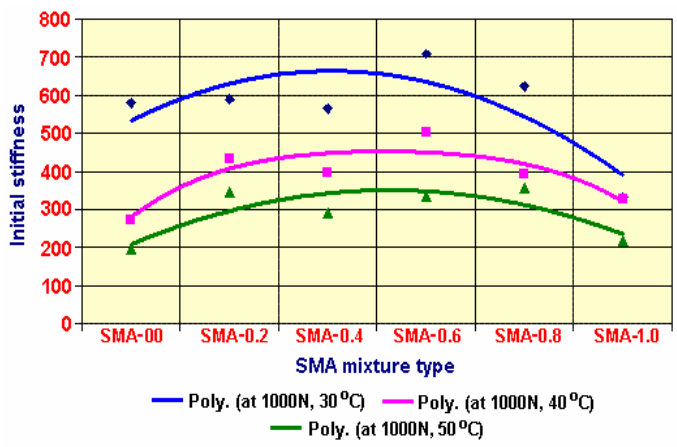

(a) Applied load $1000 \mathrm{~N}$

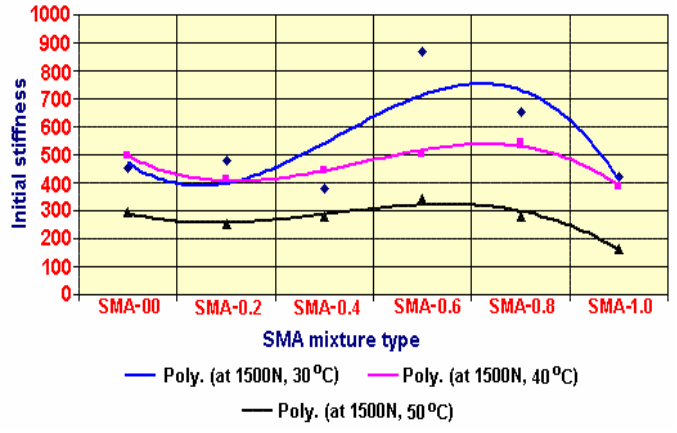

(b) Applied load $1500 \mathrm{~N}$

Fig. 9: Initial stiffness vs asphalt blend for various temperatures

versus various fiber proportions tested at different temperature and loads. The results showed that the maximum initial stiffness was attained with a fiber range between $0.4 \%-0.6 \%$.

\section{CONCLUSION}

The following conclusions are drawn from this study.

* The cellulose oil palm fibers (COPF) of sizes between 50 and 100 micron, pre-blended in PG6422 binder with fiber proportions of 0.2, 0.4, 0.6, 0.8 and $1.0 \%$ by weight of aggregates, showed improved rheological properties. The tests showed that the PG64-22 binder could be modified and raised to PG70-22 with the COPF.

* The optimum asphalt contents for SMA mixes without the COPF was slightly lower than those without the COPF. SMA without fibers had an optimum asphalt content ranging from 6.39 to $6.69 \%$, whilst SMA mixes with the fibers had a range of 6.30 to $6.84 \%$.

* The use COPF was found to improve the fatigue performance of SMA. The fatigue life increased to a maximum at fiber content of about $0.6 \%$. Likewise, the tensile stress and stiffness also showed a similar trend in performance. The initial strains of the SMA mix at were lowest at fiber content of $0.6 \%$. A similar trend was also observed for the initial stiffness of the SMA mix. Maximum stiffness values were observed at about $0.4 \%$ $0.6 \%$ fiber content. 


\section{REFERENCES}

1. Public Works Department Malaysia (PWD), 1999. Malaysian roads general information. Road Branch, Public Work Department, Kuala Lumpur.

2. Public Works Department, Malaysia. (PWD), 2000. Malaysian roads general information. Road Branch, Public Work Department, Kuala Lumpur.

3. Aik, A., 2001. A study on truck overloading along K.L-Karak highway. M. Sc. Thesis, UPM. Unpublished.

4. Gram, H.E and P. Nitniyongsul, 1987. Durability of natural fibers in cement-based roofing sheets. Proc. Symp. Building Materials for Low Income Housing, Bangkok, pp: 328-334.

5. Decoene, Y., 1990. Contribution of cellulose fibers to the performance of porous asphalts. Transportation Research Record. No. 1265, pp: 82.

6. Muniandy, R., 2004. Effect of cellulose oil palm fibers in the fatigue performance of Stone Matrix Asphalt. Ph. D. Thesis. University Putra Malaysia. Unpublished.
7. Little, D.N., 1991. An evaluation of asphalt additives to reduce permanent deformation and cracking in asphalt pavements; a brief synopsis of on-going research. Proc. Association of Asphalt Paving Technologist, 55: 315-319.

8. Brown, E.R., 1992. Experiences with stone matrix asphalt in the United States. National Center for Asphalt Technology Publication, USA.

9. Stuart, K.D., 1992. Stone Mastic Asphalt (SMA) mixture designs. FHWA-RD-92-006 Report, Federal Highway Administration, USA.

10. McDaniel, P., 1992. Stone mastic asphalt. Experimental Project No. Mo91-05 Initial Report, Missouri Highway and Transportation Research Board, USA.

11. Asphalt, 2002. Asphalt price list report. Asphalt Technology Sdn. Bhd., Malaysia.

12. Asphalt Institute, 1997. Mix design methods for asphalt. Manual Series No. 2 (MS-02). Asphalt Institute. Lexington, KY. 